\title{
Experimental study on spray and combustion of butanol-diesel blends in
}

\section{a constant volume combustion vessel}

\author{
Yu Zhang ${ }^{1}$, Ronghua Huang ${ }^{* 1}$, Sheng Huang ${ }^{1}$, Yinjie Ma ${ }^{1}$, Shijie $\mathrm{Xu}^{1}$ \\ 1. State Key Laboratory of Coal Combustion, Huazhong University of Science and Technology, \\ Wuhan, China
}

\begin{abstract}
Keywords:Butanol-diesel blends;Spray; Combustion;Experimental study
Abstract:Butanol is averypromisingalternativefueland able to be directly used in diesel engines. Visualization studies about spray and combustion of butanol-diesel blends are still scarce. In this work, a constant volume combustion vesselis used to study spray and combustioncharacteristics of butanol-diesel blends.Ambient oxygen concentration, ambient temperature and butanol concentration range from $9 \%$ to $21 \%$, from $800 \mathrm{~K}$ to $1200 \mathrm{~K}$ and from $0 \%$ to $20 \%$, respectively. Results show that the ascent stage of the FINL under $21 \%$ approximately coincides with that under $15 \%$ at $1200 \mathrm{~K}$. The FLOL of $21 \%$ is approximately equal with that of $15 \%$ at $1200 \mathrm{~K}$.The TINL of oxygen concentration $15 \%$ is the greatest at $1200 \mathrm{~K}$. However, the TINL of $21 \%$ is higher than that of $15 \%$ at $800 \mathrm{~K}$. These results can become important references for the choice of working conditions (EGR rate,injection timing and butanol concentration).
\end{abstract}

\section{Introduction}

Butanol, a kind of renewable fuels, has drawn a lot of attentions in recent years due to limited fossil fuel resources on earth. Because oxygen content in butanol and excellent miscibility with diesel, butanol is a promising alternative fuel in diesel engine.

$\mathrm{Wu}$ et al.[1-4]utilizeda constant volume combustion vessel to study the effect of different ABE proportions onspray and combustion.Results indicated that addition of ABE prolongedthe ignition delay and the flame lift-off length (FLOL), but reduced the peak of space integrated natural luminosity (SINL) and time integrated natural luminosity (TINL). Butanol has several advantages over ethanol includinghigher energy density, more excellent miscibility with diesel and much less hygroscopic.Compared to diesel, butanol is featured by lower viscosity, lower surface tension, higher latent heat and lower cetane number. These features of butanol areconductive to enhancing atomization and prolonging the ignition delay. So far, the majority of studies on butanol-diesel blends have been conducted on engine benches. Fundamental characteristics of spray and combustion under various conditions, which are not easily obtained through engine bench tests, are still deficient.Based on this situation, we investigated the impact of different conditions on basic spray and combustion characteristics of butanol-diesel blendsthrough a constantvolume combustion vessel.

\section{Experimental facilities and conditions}

The constant volume combustion vessel with acubic inner lengthof 134mmwas used in this study (seeFig.1).The vesselbodywas heated to $383 \mathrm{~K}$ to prevent water condensation on optical 
windows.The schlierensystem witha halogen lamp and a pair of $150 \mathrm{~mm}$ paraboloidmirrors was used to visualize the development of spray and combustion. The high speed digital camera (IDT MotionPro Y4-S1), which was set to $20000 \mathrm{fps}$ with a resolution of $640 \times 280$ pixels, was used to record images of the spray and combustion process. By utilizing current optical setup, the spatial resolutionof images was $0.204 \mathrm{~mm} /$ pixel.FromFig.1, pressure profiles of combustion processesare measured by apiezoelectricpressure transducer (Kistler 6052C), a charge amplifier (Kistler 5018) and a DAQ card (NI USB-6251M).

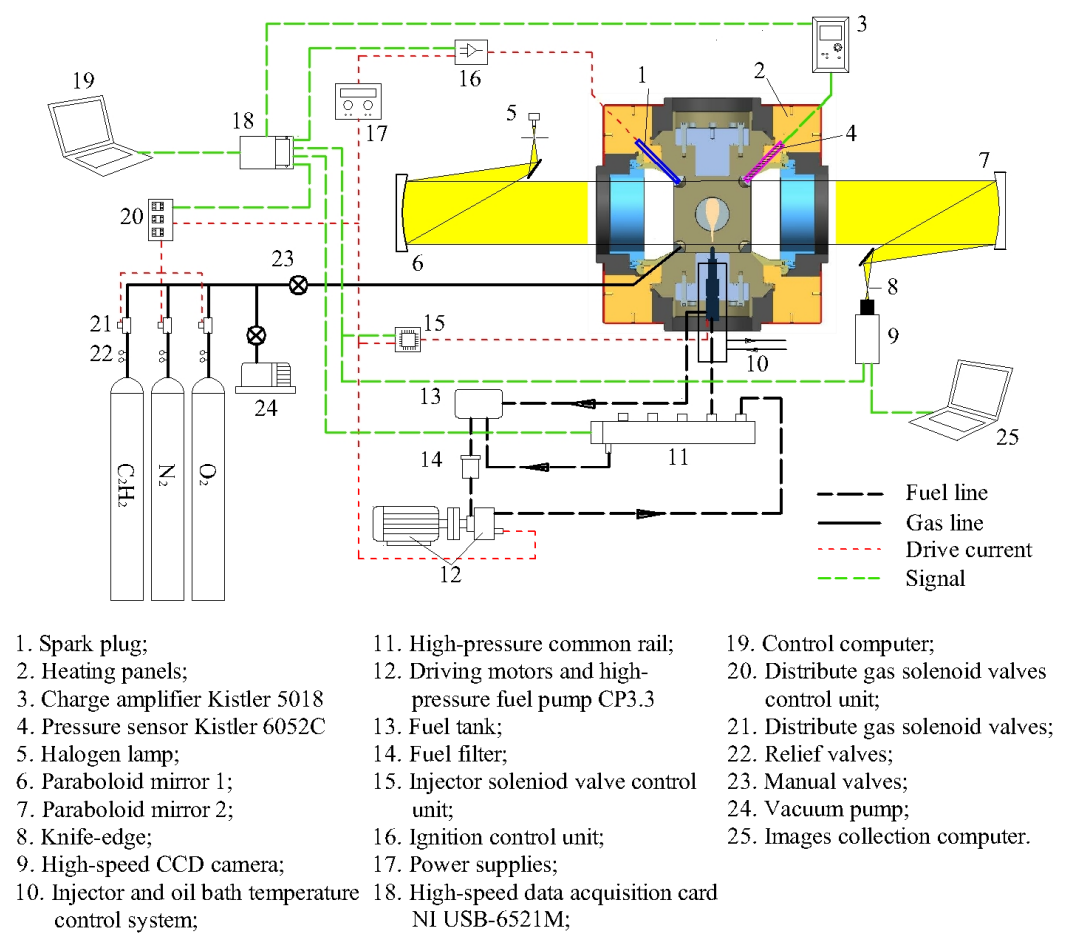

Fig.1Schematic of constant volume combustion vessel[5]

In order to avoid over-exposure and observe the flame luminosity distribution, two ND 8 filters were placed in front of a 100 mmfocal length lens (Tokina $100 \mathrm{~mm}$ F2.8 macro).Two ND8 filters reduced the brightness to its $1 / 8$ each and $1 / 64$ totally[5].Duringeverytestprocess, thecameraand pressure acquisition system beganrecordingaftertriggeredbyaTTLfallingedgesignalsynchronizedwithinjection signal [5]. Besides, the time interval between thestartofinjection(SOI) and injection signal should be obtained through the high speed digital camera. TheSOI was regarded as the original point of flame images and pressure datum.

Thestartofcombustion(SOC)wasdefinedasthetimingwhen15\%oftotalheatreleaseisreached[3].Thus, ignitiondelaywasdeterminedastheperiodbetweentheSOCandthe SOI[2].In order to eliminateenvironmentdisturbances, baselinebackground, the framerightbefore SOI, was subtracted from flame images [5]. In addition, the threshold was set to $15 \%$ of the maximum pixel value to avoid noise [2].The SINL was calculated by integrating the pixel values over the entire image[3].The TINL was calculated by further integrating the SINL with time[3].

The experiment is conducted withthree different butanol concentrations-B00, B10, B20 (B20 represents the blend of 20\% (mas.) butanol and $80 \%$ (mas.) diesel). Main reasons for theselection of 
butanol proportionsare as follows: (1). If butanol concentration is too low, the influence of butanol on spray and combustion can't be observed;(2). If butanol proportion is in a large amount, it makes combustion unstable especially under cold start condition;(3). Higher ratio of butanol ( $\geq 20 \%)$ contributes to precursors of PAHs such as toluene and benzene[6]. Different ambient oxygen concentrations $(21 \%, 15 \%$ and $9 \%)$ and ambient temperatures $(800 \mathrm{~K}, 1000 \mathrm{~K}$ and $1200 \mathrm{~K})$ correspond to different EGR rates and injection timings, respectively.If the early injection strategy is adopted, the start of combustion (SOC)is closely related to ignition delay.

\section{Results and discussion}

The natural luminosity results from two sources:chemiluminescence and soot incandescence. The natural luminosity of soot incandescence is much stronger than that of chemiluminescence[3].After using ND filters,chemiluminescenceofradicalssuchasOHisfilteredalmostentirely[5].Thus it's reasonable to reckon thatnatural luminositystands forsoot incandescence.Furthermore, the soot luminosity is related to two parameters: soot concentration and soottemperature[4].Soot formation mainly depends on local flame temperature and local equivalence ratio.

Because spray images for different fuels under various conditions are very similar in terms of flame structure, only images of B10 are shown in Fig. 2. The orifice of the injector is located on the left side of images. Raw pictures acquired by the high speed camera are gray images, which are not easily recognized by eyes.Thus the pseudo-color mapsare created by matlab, with yellow and red for flame and black for background. It's obviously observed that the natural flame luminosity at $800 \mathrm{~K}$ and $9 \%$ is barely detectable after using two ND filters.Jangi et al.[7]made use of numerical simulation to study the effect of oxygen concentrations on combustion, and indicated that the highest flame temperature at $1000 \mathrm{~K}$ and $10 \%$ was only $1980 \mathrm{~K}$. Lower ambient temperature and oxygen concentration are likely to reduce flame temperature further. Soot can't be created if the flame temperature is below $1400 \mathrm{~K}-1600 \mathrm{~K}[8]$. Therefore, it's reasonably believed that little soot is produced at the condition of $800 \mathrm{~K}$ and $9 \%$.

For all tested cases, there is a stable region withoutnatural luminosity between the orifice and flame before $2.5 \mathrm{~ms}$. Afterwards,flame luminosity rapidly spreads towards the orifice at $3.0 \mathrm{~ms}$ and fiercely propagates to the right side of the image like wavelikestructures after 3.0 msowing to the weakened spray momentum. This speed of flame propagation after injection becomes progressively faster with the increase of oxygen concentration, because high oxygen content enter into the interior of spray and acceleratessoot oxidation. The rules of change about flame also are presented in Fig. 3 (a) and (b). 


\begin{tabular}{|c|c|c|c|c|c|c|c|c|c|}
\hline \multirow{2}{*}{$\begin{array}{c}\mathrm{t} \\
(\mathrm{ms})\end{array}$} & \multicolumn{3}{|c|}{$800 \mathrm{~K}$} & \multicolumn{3}{|c|}{$1000 \mathrm{~K}$} & \multicolumn{3}{|c|}{$1200 \mathrm{~K}$} \\
\hline & $21 \% \mathrm{O}_{2}$ & $15 \% \mathrm{O}_{2}$ & $9 \% \mathrm{O} 2$ & $21 \% \mathrm{O}_{2}$ & $15 \% \mathrm{O}_{2}$ & $9 \% \mathrm{O}_{2}$ & $21 \% \mathrm{O}_{2}$ & $15 \% \mathrm{O}_{2}$ & $9 \% \mathrm{O}_{2}$ \\
\hline 0.5 & 4 & & & $\infty$ & $=$ & & ه & $*$ & $\mathrm{t}$ \\
\hline 1.0 & $\infty$ & E & & $\alpha$ & $\approx$ & e & - & $k$ & $m$ \\
\hline 1.5 & $<$ & 52 & & $=$ & +2 & $2^{n}$ & $<$ & $\infty$ & 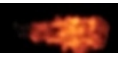 \\
\hline 2.0 & $\infty$ & knty & & $\infty$ & 4 & $x^{2}$ & - & $\infty$ & $2 x$ \\
\hline 2.5 & 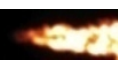 & $\mathrm{ces}^{2}$ & & & $\infty$ & 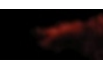 & & 4 & 28 \\
\hline 3.0 & & not & & & & 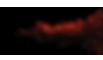 & & $\infty$ & $\cos 2$ \\
\hline 3.5 & & was & & & -2 & 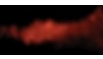 & - & $a$ & and \\
\hline 4.0 & & $2 x$ & & & 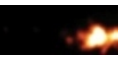 & a & & & a \\
\hline 4.5 & & & & & & da & & & A \\
\hline 5.0 & & & & & & 시 & & & 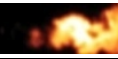 \\
\hline
\end{tabular}

Fig. 2 Natural flame luminosity of B10.
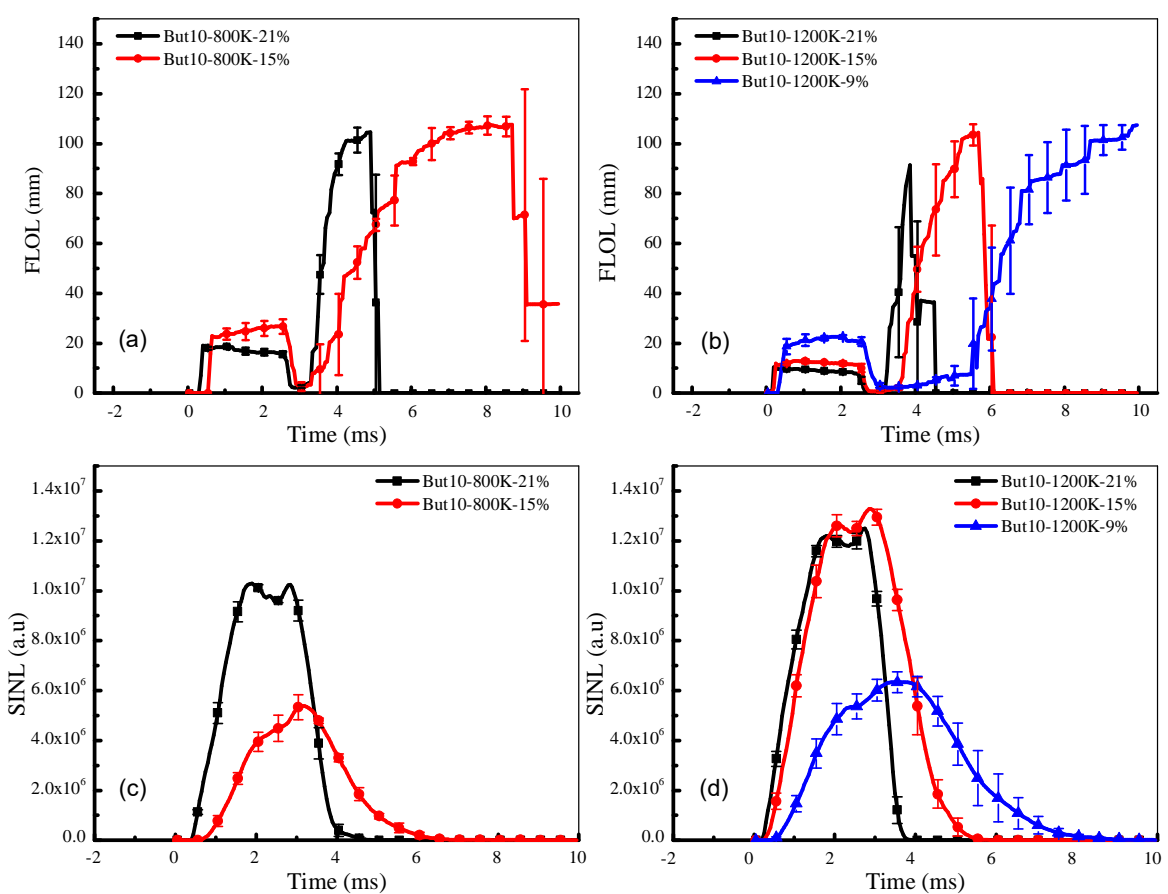

Fig. 3 The effect of oxygen concentration on FLOL and SINL 


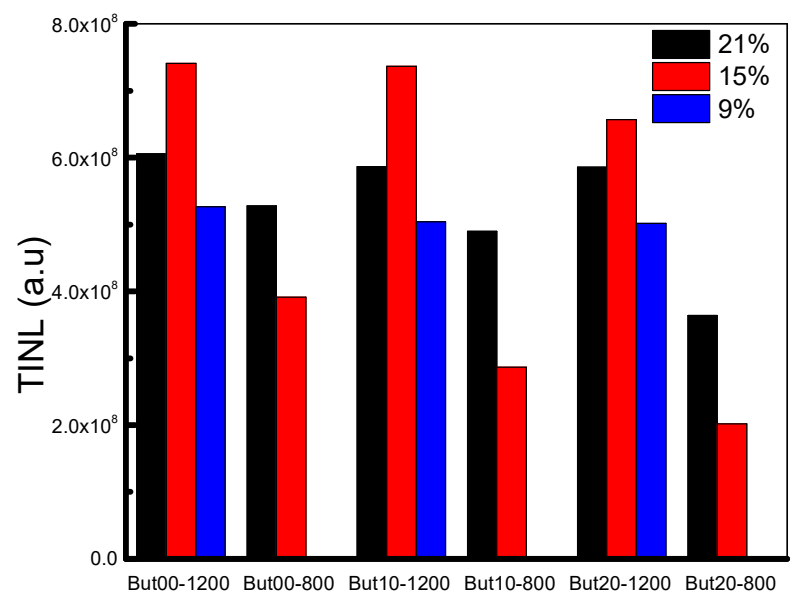

Fig. 4 The effect of oxygen concentration on TINL

As shown in Fig. 4, theTINLof $15 \%$ is the largest at $1200 \mathrm{~K}$, while theTINL of $21 \%$ is larger than that of $15 \%$ at $800 \mathrm{~K}$. At the ambient temperature of $1200 \mathrm{~K}$, flame luminosity and structure of $15 \%$ are extremely similar to those of $21 \%$ before $3.0 \mathrm{~ms}$ (see Fig. 2). From Fig. 3 (d), one also observes that the SINL curve of $15 \%$ and $21 \%$ almost coincide with each other before 3.0 ms.Generally,theoverallignitiondelayofthespraycombustionconsistsoftwoparts: physicaldelay and chemicaldelay. Since the ambient oxygen concentration has little impact on liquid penetration length[3], the oxygen concentration which doesn't work on physical delay plays a role in chemical delay. In spite of the dilution effect due to the decrease of oxygen concentration (from $21 \%$ to $15 \%$ ), the ignition delays and FLOL of $15 \%$ and $21 \%$ both are very short because high ambient temperature $(1200 \mathrm{~K})$ is the dominant factor. As stated earlier, flame disappearsfaster with the increase of oxygen concentration, therefore the TINL of $15 \%$ is more than that of $21 \%$ at $1200 \mathrm{~K}$. Because the ambient temperature no longer is dominant with the decrease of ambient temperature, the dilution effect of low oxygen concentration gets more and more important. Therefore, FLOL increase with the decrease of oxygen concentration at $800 \mathrm{~K}$ (see Fig. 3 (a)). The larger gap between liquid penetration length and FLOL allows more air entrained into the spray region, which result in the decrease of SINL (see Fig. 3 (c)). Finally, TINL gradually decrease with the decrease of oxygen concentration at $800 \mathrm{~K}$.

\section{Conclusion}

A constant volume combustion vessel was used to study spray and combustion of butanol-diesel blends under different ambient condition. The following major conclusionswere drawn from this study.

(1). At the ambient temperature of $1200 \mathrm{~K}$, the ascent stage of the FINL under $21 \%$ approximately coincides with that under $15 \%$. The FLOL of $21 \%$ is approximately equal with that of $15 \%$.

(2). The TINL of $15 \%$ was the largest under $1200 \mathrm{~K}$, whilethe TINL of $21 \%$ was larger than that of $15 \%$ under $800 \mathrm{~K}$. 


\section{Acknowledgement}

This work was supported by DONGFENG COMMERCIAL VEHICAL.

\section{References:}

[1]. Wu H, Nithyanandan K, Zhou N, Lee TH, Lee CF, Zhang C. Impacts of acetone on the spray combustion of Acetone-Butanol-Ethanol (ABE)-Diesel blends under low ambient temperature. Fuel 2015;142:109-116.

[2]. $\mathrm{Wu} \mathrm{H}$, Nithyanandan $\mathrm{K}$, Zhang $\mathrm{J}$, Lin $\mathrm{Y}$, Lee $\mathrm{TH}$, Lee CF. Impacts of Acetone-Butanol-Ethanol (ABE) ratio on spray and combustion characteristics of $\mathrm{ABE}-$ diesel blends. Appl Energ 2015;149:367-378.

[3]. Wu H, Nithyanandan K, Lee TH, Lee CF, Zhang C. Spray and combustion characteristics of neat Acetone-Butanol-Ethanol, n-Butanol, and diesel in a constant volume chamber. Energ Fuel 2014;28:6380-6391.

[4]. Wu H, Huo M, Zhou N, Nithyanandan K, Lee C, Zhang C. An experimental investigation of the combustion characteristics of Acetone-Butanol-Ethanol-Diesel blends with different ABE component ratios in a constant volume chamber.: SAE Technical Paper; 2014. p.

[5]. Huang S, Deng P, Huang R, Wang Z, Ma Y, Dai H. Visualization research on spray atomization, evaporation and combustion processes of ethanol-diesel blend under LTC conditions. Energ Convers Manage 2015;106:911-920.

[6]. Choi B, Jiang X, Kim YK, Jung G, Lee C, Choi I. Effect of diesel fuel blend with n-butanol on the emission of a turbocharged common rail direct injection diesel engine. Appl Energ 2015;146:20-28.

[7]. Jangi M, Lucchini T, D Errico G, Bai X. Effects of EGR on the structure and emissions of diesel combustion. P Combust Inst 2013;34:3091-3098.

[8]. Wang H. Experimental and Numerical Studies on the Soot Formation Mechanism: Tianjin University; 2012. 